Artigo de Revisão

\title{
Biologia molecular nas doenças do neurônio motor
}

\author{
Edmar Zanoteli', Ana Beatriz Alvarêz Peres², Acary Souza Bulle Oliveira ${ }^{3}$, Alberto Alain Gabbai ${ }^{4}$
}

\section{RESUMO}

As motoneuronopatias correspondem a um grupo amplo de doenças caracterizadas pelo comprometimento dos neurônios motores superior, inferior ou ambos. Na criança a forma mais comum de motoneuronopatia é a amiotrofia espinhal progressiva, associada com mutações no gene SMN (sobrevida do neurônio motor) em mais de $90 \%$ dos casos. No adulto (doenças do neurônio motor), apenas uma percentagem menor que $15 \%$ dos casos correspondem a formas familiares. Neste grupo a forma mais comum está associada com mutações no gene da enzima superóxido dismutase (SOD1). No entanto, novos locus genéticos vêm sendo freqüentemente descritos nas formas de doença do neurônio motor do adulto. O objetivo deste trabalho é o de apresentar uma revisão da literatura dos conhecimentos atuais quanto aos aspectos genéticos das motoneuronopatias.

Descritores: Doenças do neurônio motor, Esclerose lateral amiotrófica, amiotrofia espinhal progressiva, Aspectos genéticos.

\section{SUMMARY}

The motor neuron diseases are a group of diseases characterized by upper motor neuron, lower motor neuron or both involvement. The most common form of motor neuron disease in the infancy is the spinal muscular atrophy associated with mutations on SMN gene in more than 90\% of cases. In adult patients less than $15 \%$ of cases are familial. In this group the most frequent disease is associated with mutations on SOD1 gene. However, new genetic loci have been frequently described associated with motor neuron disease of adults. The objective of this study is to review the recent aspects of molecular biology in the motor neuron diseases.

Key words: Motor neuron diseases, Lateral sclerosis amyotrophy, Spinal muscular atrophy, Genetic aspects

\section{INTRODUÇÃO}

Motoneuronopatia é um termo genérico utilizado para incluir um grupo de doenças degenerativas caracterizadas pelo comprometimento primariamente do corpo celular do motoneurônio (neurônios motores corticais, do tronco cerebral e espinhais (segundo neurônio)). $\mathrm{Na}$ infância a principal forma de motoneuronopatia é a amiotrofia espinhal progressiva (AEP), uma doença de herança autossômica recessiva com grande variabilidade quanto a época de início e gravidade do comprometimento motor ${ }^{1}$. A poliomielite se caracteriza por paralisia flácida assimétrica dos membros decorrente de processo infeccioso viral acometendo as células do corno anterior da medula espinhal. Devido a vacinação em massa da população contra o poliovírus, casos novos da doença não têm sido registrados. No entanto, na vida adulta alguns pacientes com seqüela de poliomielite desenvolvem uma piora lentamente progressiva do quadro motor caracterizando a síndrome pós-pólio.

As quatro principais síndromes clínicas de início na vida adulta incluídas dentro das motoneuronopatias, também conhecidas como doenças do neurônio motor (DNM), são: atrofia muscular progressiva (AMP), esclerose lateral primária (ELP), paralisia bulbar progressiva (PBP) e esclerose lateral amiotrófica (ELA). A denominação ELP é utilizada naqueles casos em que houver acometimento puro do neurônio motor superior (NMS). O termo AMP é empregado quando houver envolvimento isolado do neurônio motor inferior (NMI). O envolvimento combinado de lesão do NMS e NMI caracteriza o quadro de ELA. O termo PBP é empregado quando ocorre acometimento isolado ou predominante dos neurônios motores bulbares. No entanto, há muita discussão na literatura se estas síndromes devam ser consideradas entidades isoladas ou se estariam inseridas no contexto da ELA, correspondendo apenas fases ou manifestações clínicas distintas da mesma doença ${ }^{2,3}$.

A AMP é um tipo de DNM que se caracteriza pelo acometimento puro do $\mathrm{NMI}$, com ou sem manifestação de fraqueza da musculatura bulbar. Representa cerca de 5 a $20 \%$ dos casos de DNM. Manifesta-se clinicamente com fraqueza muscular, hipotonia, atrofia e fasciculações,

Trabalho realizado na Universidade Federal de São Paulo - Escola Paulista de Medicina - UNIFESP-EPM.

1 - Professor Adjunto Substituto, Disciplina de Neurologia, UNIFESP

2 - Doutora em Medicina, Centro de Genética Médica, Departamento de Morfologia, UNIFESP

3 - Doutor em Neurologia, Chefe do Setor de Investigação em Doenças Neuromusculares, Disciplina de Neurologia, UNIFESP

4 - Professor Titular, Chefe da Disciplina de Neurologia da UNIFESP 
geralmente de início assimétrico e nos membros superiores e posteriormente envolvendo os membros inferiores e os músculos bulbares. Em geral, os homens são mais afetados que as mulheres e o início das manifestações ocorre mais precocemente que na ELA ${ }^{2}$. O principal diagnóstico diferencial deve ser feito com neuropatia motora pura com bloqueio de condução, já que ambas podem ocasionar um quadro clínico bastante semelhante, principalmente no início da evolução da doença. Anticorpos contra o gangliosídeo GM1 são encontrados em torno de 22 a $84 \%$ dos pacientes com neuropatia motora multifocal ${ }^{4}$. Confusões podem ainda se estabelecer entre os nomes AMP e AEP, sendo que, o quadro clínico, a faixa etária de acometimento, o prognóstico e o caráter hereditário da AEP são quase sempre suficientes para diferenciá-las.

A ELP caracteriza-se por um curso lentamente progressivo de quadriparesia espástica, reflexos tendíneos profundos exaltados, sinal de Babinski bilateral, disartria espástica e labilidade emocional (quadro pseudobulbar) ${ }^{2}$. A distribuição da fraqueza tende a ser simétrica, com o estágio final marcado por espasticidade difusa. A ELP apresenta um quadro clínico mais insidioso que o da ELA, de início em geral na quinta década de vida, e também um curso mais longo, maior que 3 anos ${ }^{2}$. Seguimento de longo prazo de alguns desses casos tem sugerido que sinais de comprometimento do NMI tendem a surgir nos estágios mais avançados da doença ${ }^{5}$. A ELP, como entidade nosológica distinta, permanece controversa, de um lado podendo fazer parte do contexto da paraparesia espástica hereditária e por outro da ELA.

A PBP caracteriza-se por comprometimento predominante da musculatura de inervação bulbar com ou sem envolvimento do NMS. Disartria e disfagia são os sintomas predominantes, acompanhando-se de fraqueza, atrofia e fasciculações de língua ${ }^{2}$. Associadamente, sinais de comprometimento do NMS ou labilidade emocional podem ser observados.

A ELA se caracteriza pela presença de sinais e sintomas tanto de comprometimento do NMS (espasticidade e hiperreflexia) quanto do NMI (hipotonia, arreflexia, atrofia muscular e fasciculações). É a forma mais comum de DNM de início na vida adulta e, por isso, freqüentemente, o termo ELA é utilizado indistintamente para as outras formas de DNM de início na vida adulta ${ }^{2}$. A doença afeta preferencialmente pacientes do sexo masculino e, em geral, após os 40 anos de idade. Apresenta um curso progressivo, com o óbito ocorrendo, em geral, 2 a 5 anos após o início da doença. A insuficiência respiratória com ou sem pneumonia é a principal causa de óbito, em geral associada a disfagia com broncoaspiração. Os sinais clínicos mais proeminentes são fraqueza, atrofia e fasciculações nos membros, de início assimétrico. Posteriormente a musculatura bulbar e respiratória são também afetadas. Os pacientes não apresentam comprometimento sensitivo, autonômico ou visual. Os nervos que controlam os movimentos oculares, e os segmentos sacros inferiores da medula espinhal, que controlam os esfíncteres, não são afetados. As funções corticais superiores, como inteligência e memória, não são comprometidas. Os pacientes podem apresentar labilidade emocional e depressão.

De acordo com os critérios de "El Escorial" revisados em 20006 , existem vários tipos clínicos de ELA e síndromes relacionadas à ELA que devem ser reconhecidas: A) ELA esporádica, que ocorre isoladamente; B) ELA familiar, em alguns casos associada com mutações no gene da enzima superóxido dismutase (SOD1) e deficiência de hexosaminidase $A / B$; C) síndrome ELA "plus", na qual a ELA está associada com manifestações clínicas de outras doenças neurológicas (forma de Guam, sinais extrapiramidais, degeneração cerebelar, demência, envolvimento do sistema nervoso autônomo e anormalidades sensitivas e dos movimentos oculares); D) ELA com anormalidades laboratoriais de significado incerto, nas quais incluemse as gamopatias monoclonais, autoanticorpos (GM1), endocrinopatias, linfoma, infecções (HIV-1, HTVL-1, varicela zoster, brucelose, borreliose, sífilis), toxinas exógenas (chumbo, mercúrio, alumínio); e E) síndromes que mimetizam a ELA, tais como a síndrome pós-pólio e as neuropatias motoras multifocais com ou sem bloqueio de condução.

\section{Etiologia da ELA}

Vários fatores têm sido implicados na patogênese da doença, tais como a deficiência de fatores tróficos, os defeitos no transporte axonal, disfunção dos receptores androgênicos, infecções virais, autoimunidade, fatores tóxicos exógenos, excitotoxocidade endógena, mutações genéticas e anormalidades das mitocôndrias ${ }^{7}$. Com exceção dos casos familiares, nenhum destes fatores foi identificado como sendo isoladamente a causa da doença.

As neurotrofinas têm influência no desenvolvimento e sobrevida dos neurônios, além de exercerem papel protetor e restaurador das funções neuronais ${ }^{8}$. Os mais implicados são: fator neurotrófico ciliar (CNTF), fator neurotrófico derivado do cérebro (BDNF), neurotrofinas 3 (NT-3) e 4 (NT-4), fator neurotrófico derivado da glia (GDNF) e fator de crescimento tipo insulina (IGF-1). Muitas destas neurotrofinas funcionariam como potentes protetores neuronais contra o glutamato ${ }^{9}$.

As proteínas neurofilamentares (NF) são importantes no transporte axonal e na determinação da forma celular e do calibre dos axônios. O acúmulo de proteínas NF no axônio levaria a alteração na densidade dos elementos do citoesqueleto axonal, provocando edema e morte neuronal. Estas anormalidades poderiam ser a causa ou conseqüência da degeneração neuronal ${ }^{7}$. Títulos elevados de anticorpos antigangliosídeos (GM1), antiasialo-gangliosídeos (AGM1) e anti-sulfatídeos têm sido encontrados no soro e no líquido cefalorraqueano de pacientes com ELA, numa freqüência maior do que em indivíduos normais e com outras DNM, sugerindo que em alguns casos de ELA um mecanismo autoimune poderia estar contribuindo para a lesão do motoneurônio ${ }^{10}$.

A incidência elevada do complexo ELA/Parkinson/ demência na população da ilha de Guam tem sido associada a ingestão de produtos provenientes de palmeira, que contém uma substância chamada de B-Nmetilamino-L-alanina (BMAA) que atua com uma 
neurotoxina exógena ${ }^{11}$.

Defeitos na recaptação do glutamato extracelular ou aumento na sua liberação nos terminais nervosos levam a um acúmulo desse neurotransmissor na fenda sináptica, causando aumento na transmissão excitatória nos receptores N-metil-D-aspartato (NMDA), facilitando a entrada excessiva de cálcio nas células e por conseguinte de dano celular ${ }^{8}$. A perda da função dos transportadores de glutamato sódio-dependente produz níveis elevados de glutamato extracelular. Diferentes tipos de transportadores de glutamato, especialmente os aminoácidos excitatórios-transportadores 1 e 2 (AAET 1 e 2), têm sido estudados na ELA ${ }^{12}$.

O cálcio intracelular, em quantidade excessiva, leva a ativação de enzimas lisossomais que causam danos à célula e, uma vez no interior da mitocôndria, desencadeiam o desacoplamento da síntese de ATP da oxidação respiratória. Com a mitocôndria inativa, a produção de ATP é reduzida. A redução de ATP resulta na diminuição da atividade das enzimas $\mathrm{Ca2}+$ - ATPases, as quais provocam o aumento do cálcio intracelular, resultando num ciclo vicioso e gerando morte celular ${ }^{13}$.

\section{ELA familiar}

Em torno de 5 a $10 \%$ dos casos de ELA são familiares. A idade de início tende a ser 10 a 15 anos mais cedo do que para a ELA esporádica, podendo ainda apresentar um início juvenil ou adulto jovem. A sobrevida tende a ser menor que nos casos de ELA esporádica. Aproximadamente $10 \%$ dos casos familiares são causados por mutações no gene da enzima da cobre/ zinco superóxido dismutase (SOD1) no cromossomo $21^{14}$. Normalmente, a SOD1 realiza a dismutação do radical livre superóxido $\left(\mathrm{O}_{2}\right)$ em água oxigenada $\left(\mathrm{H}_{2} \mathrm{O}_{2}\right)$ e oxigênio molecular $\left(\mathrm{O}_{2}\right)$. Acredita-se que a diminuição da atividade da SOD leva ao acúmulo do íon superóxido, que liga-se então ao óxido nítrico (NO) para formar os radicais livres peroxidonitrila (ONOO-) e hidroxila $(\mathrm{OH})$. O acúmulo de radicais livres é altamente lesivo para a célula, pois provoca peroxidação das membranas e modificação de proteínas (nitritação aberrante dos resíduos de tirosina), culminando com a morte do motoneurônio (Figura 1) ${ }^{7}$. Já foram descritas mais de 90 mutações dispersas pelos 5

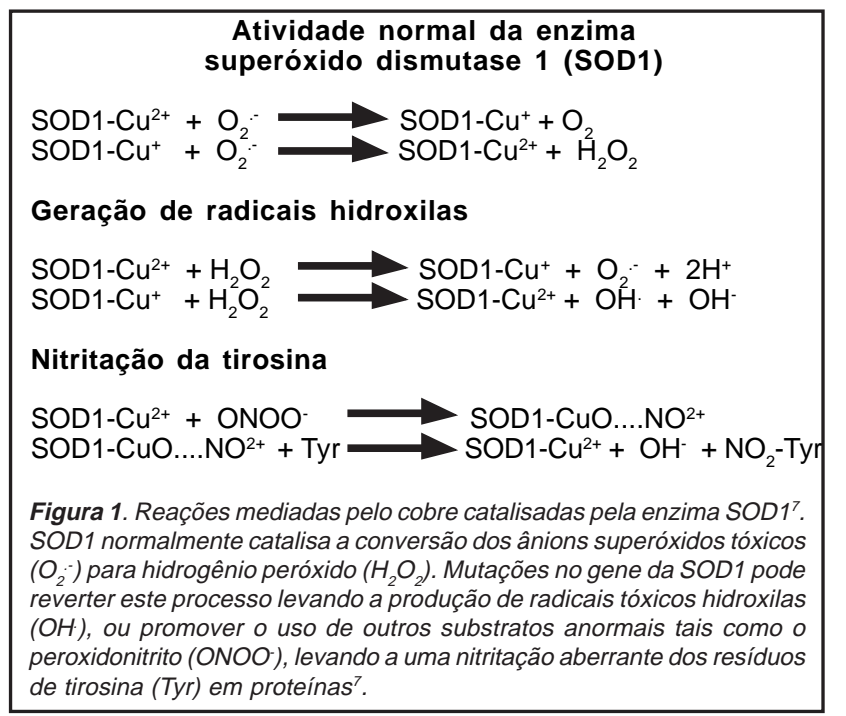

exons do gene $S O D 1$, na grande maioria dos casos com herança autossômica dominante ${ }^{14-16}$. A substituição da valina pela alanina na posição 4 (A4V) é a mutação mais freqüente $(50 \%$ dos casos) e correlaciona-se com uma sobrevida menor que nas outras formas familiares ${ }^{14,16}$. Ao contrário, a presença das mutações G37R, G41D e G93C prediz uma sobrevida mais longa ${ }^{16}$. A presença das mutações G37R ou L38V correlaciona-se com um início mais precoce do quadro ${ }^{16}$. Giess et al $(2002)^{17}$ mostraram que em pacientes com ELA familiar decorrentes de mutações no gene SOD1 e também em casos esporádicos de ELA o gene do fator neurotrófico ciliar (CNTF) teria um efeito modificador, levando a um início mais precoce da doença ${ }^{17}$.

Hentati et al (1998) $)^{18}$ mapearam um outro "locus" no cromossomo 15 (15q15.1-q21.1) em pacientes com ELA de herança autossômica recessiva e com início mais precoce (ELA tipo 5). Chance et al (1998) ${ }^{19}$ analisaram uma grande família com quadro clínico de ELA com início juvenil (segunda década), de evolução lentamente progressiva, e de herança autossômica dominante, e mapearam o gene no cromossomo 9 (9q34) (ELA tipo 4).

Yang et al (2001) ${ }^{20}$ e Hadano et al (2001) ${ }^{21}$ identificaram mutações no gene de uma proteína denominada "alsin" em raros casos de ELA juvenil de herança autossômica recessiva (ELA tipo 2). Mutações no gene "alsin" também foram descritas em pacientes com ELP de início juvenil. Eymard-Pierre et al (2002) ${ }^{22}$ descreveram mutações no gene "alsin" em várias famílias com uma forma grave de paraparesia espástica de início juvenil. Assim, mutações no gene "alsin" seriam responsáveis em alguns casos familiares pela degeneração dos neurônios motores superiores, de início na infância (paraparesia espástica hereditária) ou juvenil (ELP), com ou sem envolvimento dos neurônios motores inferiores (ELA juvenil).

Mais recentemente, em uma grande família européia com ELA, de herança autossômica dominante, e de início na vida adulta, Hand et al $(2002)^{23}$ identificaram um novo "locus" no cromossomo 18 (18q21) (ELA tipo 3).

\section{Atrofia muscular espinhal (AEP)}

A AEP é uma doença genética de início na infância que afeta o corpo do neurônio motor no corno anterior da medula espinhal, ocasionando hipotonia e fraqueza musculares difusas simétricas de predomínio nas porções proximais dos membros e arreflexia tendínea profunda ${ }^{1}$. Conforme a época do início da doença e a gravidade do comprometimento motor, a AEP tem sido dividida em três formas ${ }^{24}$ : O tipo I (doença de WerdnigHoffmann, ou forma grave) é caracterizado por um início precoce, antes dos 6 meses de vida, e grave comprometimento motor e respiratório. As crianças não chegam a sentar sem apoio e mais de $90 \%$ delas não sobrevivem após os 2 anos de idade. O tipo II (forma intermediária) apresenta um início antes dos 18 meses de vida; as crianças são capazes de sentar sem apoio, porém não chegam a deambular. O tipo III (doença de Kugelberg-Welander, ou forma leve) possui um quadro clínico mais brando, com início após os 2 anos de vida, caracterizado por fraqueza e atrofia musculares das cinturas; os pacientes, em geral, apresentam algum período de deambulação. 
Em 1995, dois genes candidatos para a AEP foram identificados no cromossomo 5: SMN (sobrevida do neurônio motor) ${ }^{25}$ e NAIP (proteína inibidora da apoptose neuronal) ${ }^{26}$. Nesta região existem duas cópias homólogas do gene SMN (uma cópia telomérica e outra centromérica) (Figura 2). A cópia telomérica, também chamada de SMN1, difere da cópia centromérica (SMN2) por apenas 5 pares de base, sendo duas nos exons 7 e 8 . Acima de $90 \%$ dos pacientes com quadro clínico de AEP são causados por deleção homozigótica do gene SMN1 (Figura 2) 25,27. Embora as duas cópias do gene sejam transcritas, apenas a cópia telomérica teria importância funcional, pois é a cópia que se encontra ausente nos casos de $\mathrm{AEP}^{25}$. Além do mais, em torno de $4 \%$ dos indivíduos normais apresentam deleção homozigótica dos exons 7 e 8 da cópia centromérica do gene $S M N^{25}$. Em um dos maiores centros de reabilitação do Brasil, analisando pacientes com AEP tipos 2 e 3 encontramos deleção do gene SMN1 em $87 \%$ dos casos $^{28}$.

Vários estudos têm mostrado que o número de cópias do gene SMN2 é maior nos pacientes com AEP tipos II e III do que no tipo I, devido a conversão do gene SMN1 em $S M N 2^{29,30}$. O maior número de cópias do gene SMN2 produziria um fenótipo mais brando, já que o SMN2 seria capaz de codificar até $20 \%$ da proteína funcional ${ }^{25,29}$. Tal observação é fortalecida pela análise da expressão da proteína SMN na medula espinhal, na qual o nível da proteína funcional produzida nos pacientes com AEP tipos II e III é maior que no tipo ${ }^{25}$.

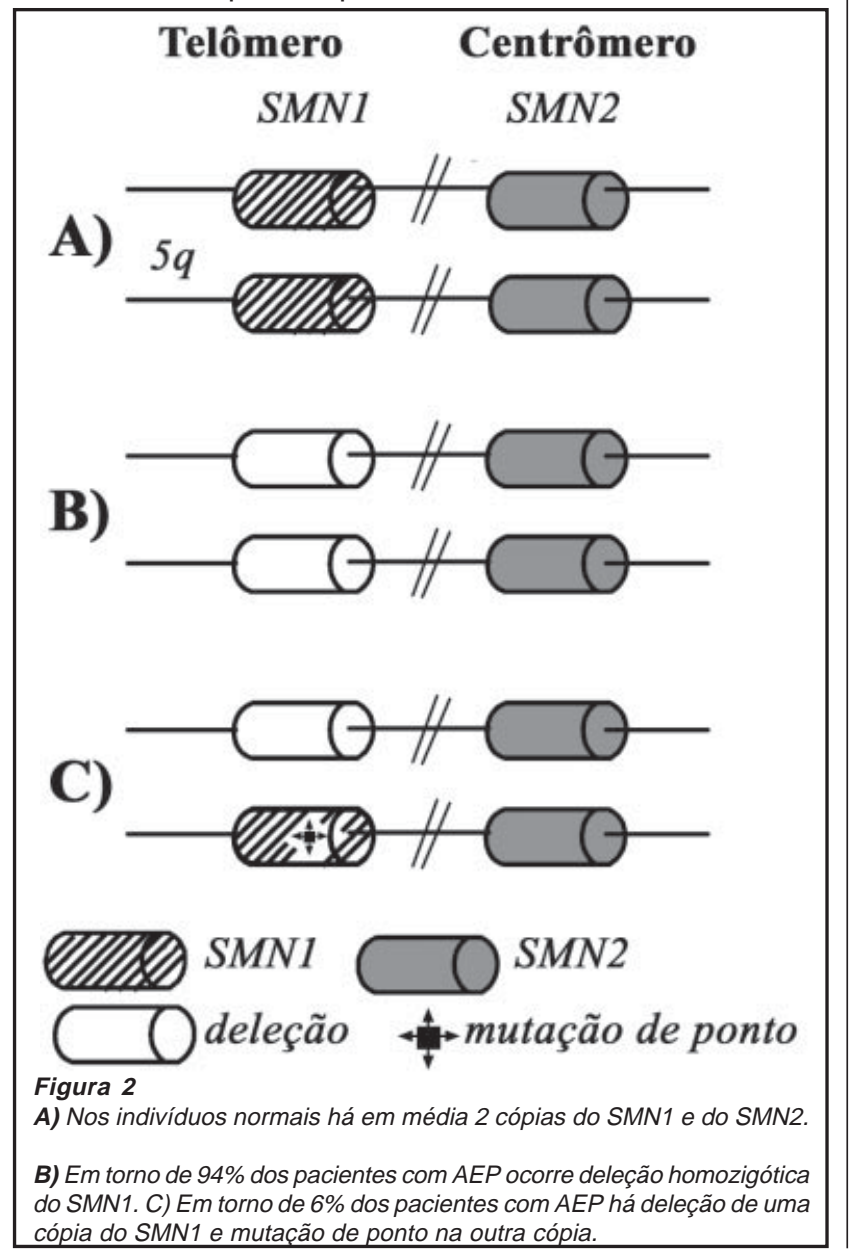

A diferença de $1 \mathrm{pb}$ no exon 7 do SMN2 afeta a eficiência da incorporação do exon 7 no RNAm, produzindo uma proteína menor e menos funcional. Assim, estudos recentes têm identificado substâncias capazes de afetar a incorporação do exon 7 no RNAm do gene, o qual favoreceria a produção de uma proteína mais funcional. Andreassi et al. (2001) ${ }^{31}$ demostraram que a aclarubicina seria capaz de aumentar a retenção do exon 7 no SMN2 transcripto, aumentando a expressão da proteína SMN em fibroblastos de crianças com AEP; e Chang et al $(2001)^{32}$ mostraram que o butirato de sódio facilitaria a incorporação do exon 7 no SMN2 transcrito, aumentando a expressão da proteína em modelos animais de AEP.

A cópia telomérica do gene NAIP pode ser distinguida do seu pseudogene centromérico pela presença do exon 5 apenas na cópia telomérica ${ }^{26}$. A ausência do exon 5 do gene NAIP tem sido observada mais freqüentemente nos pacientes com AEP tipo I do que nos tipos II e III, sugerindo a presença de uma maior deleção na AEP tipo ${ }^{26,27}$. Um outro gene também localizado no cromossômo 5 é responsável pela codificação da proteína p44, uma subunidade do fator de transcrição basal $\mathrm{TFIIH}^{33}$. Deleção deste gene tem sido observada em aproximadamente $70 \%$ dos pacientes com AEP tipo I, mas a presença da deleção nos parentes e em indivíduos normais sugere que este gene não teria importância na patogênese da $A E P^{34}$.

DNM de início na vida adulta e os genes SMNe NAIP

Moulard et al (1998) ${ }^{35}$ encontraram em um grupo de 14 pacientes com diagnóstico de AMP dois casos com deleção no gene SMN1 (configurando o diagnóstico de AEP de início tardio) e $36 \%$ com deleção do gene SMN2, uma porcentagem muito acima daquela observada na população normal (até $5 \%$ ). Nos casos de ELA (177 pacientes) e ELP (66 pacientes) os autores encontraram deleção do gene SMN2 em apenas 6,2\% e 1,5\% respectivamente; uma percentagem próxima ao esperado, comparando-se com a população normal. Os casos de ELA e ELP com deleção do gene SMN2 não apresentaram diferenças estatísticas comparando-se com os casos sem deleção considerando a época do início, a sobrevida média, e o sexo. Em contrapartida, os casos de AMP com deleção do gene SMN2 apresentaram um início mais precoce da doença e um quadro clínico mais grave com relação aos casos de AMP sem a deleção, sugerindo que de alguma forma a ausência do gene SMN2 poderia interferir na patogênese da doença, ou mesmo funcionaria como um fator de predisposição genética ${ }^{35}$. Deleção homozigótica do gene NAIP foi encontrada em apenas um caso de ELA no estudo de Jackson et al (1996) ${ }^{36}$ e no estudo de Moulard et al $(1998)^{35}$; percentagem semelhante aquela encontrada na população geral ${ }^{26}$.

\section{Conclusão}

Enquanto que mais de $90 \%$ das crianças com doença do neurônio motor possuem defeito genético já identificado (SMN), menos de $20 \%$ dos pacientes com doença do neurônio motor de início na vida adulta, possuem defeito genético identificado ou são familiares, sugerindo neste grupo um efeito acentuado de fatores exógenos. 
Muitas teorias têm sido propostas para explicar a etiopatogênese da ELA. Provavelmente mais de um fator esteja contribuindo para a morte precoce do motoneurônio. Como estes mecanismos interagem ainda não está esclarecido.

A detecção de novos genes envolvidos trará informações sobre outros possíveis mecanismos envolvidos, e assim ampliar o conhecimento dos eventos responsáveis pela morte neuronal. O uso de drogas capazes de interferir nestes mecanismos poderão prolongar a sobrevida neuronal, enquanto o desenvolvimento e a aplicação prática da terapia gênica não esteja efetivada. Uma das propostas de terapia gênica seria o uso de vetor viral para transportar o gene da EAA2 (transportador de aminoácidos excitatórios) para a medula espinhal, através de injeção intraparenquimal, com o objetivo de reduzir os níveis de glutamato ${ }^{37}$. Uma outra abordagem seria a utilização de células tronco ("stemcell”), para promover uma redução na velocidade de degeneração neuronal ${ }^{38}$.

\section{REFERÊNCIASBIBLIOGRÁFICAS}

1. Dubowitz V. Disorders of the lower motor neurone: the spinal muscular atrophies. In: Dubowitz V (ed). Muscle Disorders in Childhood. $2^{\text {nd }}$ ed. London, W.B. Saunders Co, 1995, 325-369.

2. Pringle CE, Hudson AJ, Monoz DG, Kiernan JA, Brown WF, Ebers GC. Primary lateal sclerosis. Clinical features, neuropathology and diagnostic criteria. Brain, 115:495-520, 1992.

3. Norris F, Shepherd R, Denys EUK, Mukai E, Elias L, Holden D, Norris H. Onset, natural history and outcome in idiopathic adult motor neuron disease. J Neurol Sci, 118:48-55, 1993.

4. Chaudhry V. Multifocal motor neuropathy. Semin Neurol, 48:919-926, 2000.

5. Buainain RP. Doença do neurônio motor superior de longa duração seguida por comprometimento do neurônio motor inferior. Ribeirão Preto, 2002, 134p, mestrado, Faculdade de Medicina de Ribeirão Preto, Universidade de São Paulo.

6. Brooks BR, Miller RG, Swash M, Munsat TL; World Federation of Neurology Research Group on Motor Neuron Diseases. El Escorial revisited: revised criteria for the diagnosis of amyotrophic lateral sclerosis. Amyotroph Lateral Scler Other Motor Neuron Disord, 1(5):293-9, 2000.

7. Rowland LP, Shneider NA. Amyotrophic lateral sclerosis. N Engl J Med, 344(22):1688-1700, 2001.

8. Milonas I. Amyotrophic lateral sclerosis. J Neurol, 245(2):S1-S3, 1998.

9. Corse AM, Bilak MM, Bilak SR, Lehar M, Rothstein JD, Kuncl RW. Preclinical testing of neuroprotective neurotrophic factors in a model of chronic neuron degeneration. Neurobiol Dis, 6:335-346, 1999.

10. Niebroj-Dobosj I, Jamrozik Z, Hausmanowa-Petrusewicz I, Kwiecinski H. Anti-neural antibodies in serum and cerebrospinal fluid of amyotrophic lateral sclerosis (ALS) patients. Acta Neurol Scand, 100:238-243, 1999.

11. Durlach J, Bac P, Durlach V, Durlach A, Bara M, Guiet-Bara A. Are age-related neurodegenerative diseases linked with various types of magnesium depletion? Magens Res, 10(4):339-353, 1997.

12. Sasaki S, Komori T, Iwata M. Excitatory amino acid transporter 1 and 2 immunoreactivity in the spinal cord in amyotrophic lateral sclerosis. Acta Neuropathol, 100:138-144, 2000.

13. Morrison BM, Morrison JH. Amyotrophic lateral sclerosis associated with mutations in superoxide dismutase: a putative mechanism of degeneration. Brain Res, 29:121-135, 1999.

14. Rosen DR, Siddique T, Patterson D, Figlewicz DA, Sapp P, Hentati A, Donaldson D, Goto J, O'Regan JP, Deng HX, et al. Mutations in $\mathrm{Cu} / \mathrm{Zn}$ superoxide dismutase gene are asociated with familial amyotrophic lateral sclerosis. Nature, 362:59-62, 1993.

15. Anderson PM, Nilsson P, Keranen ML, Forsgren L, Hagglund J, Karlsborg M, Ronnevi LO, Gredal O, Marklund SL. Phenotypic heterogenety in motor neuron dissease patients with cuZn-superoxide dismutase mutations in Scandinavia. Brain, 120:1723-37, 1997.

16. Cudkowicz ME, McKenna-Yasek D, Sapp PE, Chin W, Geller B, Hayden DL, Schoenfeld DA, Hosler BA, Horvitz HR, Brown RH. Epidemiology of mutations in superoxide dismutase in amyotrophic lateral sclerosis. Ann Neurol, 41(2):21021, 1997.

17. Giess R, Maurer M, Linker R, Gold R, Warmuth-Metz M, Toyka KV, Sendtner M, Rieckmann P. Association of a null mutation in the CNTF gene with early onset of multiple sclerosis. Arch Neurol, 59(3):407-9, 2002.

18. Hentati A, Ouahchi K, Pericak-Vance MA, Nijhawan D, Ahmad A, Yang Y, Rimmler J, Hung W, Schlotter B, Ahmed A, Ben Hamida M, Hentati F, Siddique T. Linkage of a commoner form of recessive amyotrophic lateral sclerosis to chromosome 15q15-q22 markers. Neurogenetics, 2(1):55-60, 1998. 
19. Chance PF, Rabin BA, Ryan SG, Ding Y, Scavina M, Crain B, Griffin JW, Cornblath DR.Linkage of the gene for an autosomal dominant form of juvenile amyotrophic lateral sclerosis to chromosome 9q34. Am J Hum Genet, 62(3):63340, 1998.

20. Yang Y, Hentati A, Deng HX, Dabbagh O, Sasaki T, Hirano M, Hung WY, Ouahchi K, Yan J, Azim AC, Cole N, Gascon G, Yagmour A, Ben-Hamida M, Pericak-Vance M, Hentati F, Siddique T. The gene encoding alsin, a protein with three guanine-nucleotide exchange factor domains, is mutated in a form of recessive amyotrophic lateral sclerosis. Nat Genet, 29(2):160-5, 2001.

21. Hadano S, Hand CK, Osuga H, Yanagisawa Y, Otomo A, Devon RS, Miyamoto N, Showguchi-Miyata J, Okada Y, Singaraja R, Figlewicz DA, Kwiatkowski T, Hosler BA, Sagie T, Skaug J, Nasir J, Brown RH Jr, Scherer SW, Rouleau GA, Hayden MR, Ikeda JE. A gene encoding a putative GTPase regulator is mutated in familial amyotrophic lateral sclerosis 2. Nat Genet, 29(2):166-73, 2001.

22. Eymard-Pierre E, Lesca G, Dollet S, Santorelli FM, di Capua M, Bertini E, Boespflug-Tanguy O.Infantile-onset ascending hereditary spastic paralysis is associated with mutations in the alsin gene. Am J Hum Genet, 71(3):518-27, 2002.

23. Hand CK, Khoris J, Salachas F, Gros-Louis F, Lopes AA, Mayeux-Portas V, Brewer CG, Brown RH Jr, Meininger V, Camu W, Rouleau GA. A novel locus for familial amyotrophic lateral sclerosis, on chromosome 18q. Am J Hum Genet, 70(1):251-6, 2002.

24. Munsat TL. Workshop report: international SMA collaboration. Neuromuscul Disord, 1:81, 1991.

25. Lefebvre S, Burglen L, Reboullet S, Clermont O, Burlet P, Viollet L, Benichou B, Cruaud C, Millasseau P, Zeviani M, et al. Identification and characterization of a spinal muscular atrophy determining gene. Cell, 80:155-65, 1995.

26. Roy N, Mahadevan MS, McLean M, Shutler G, Yaraghi Z, Farahani R, Baird S, Besner-Johnston A, Lefebvre C, Kang $X$, et al.The gene for neuronal apoptosis inhibitory protein is partially deleted in individuals with spinal muscular atrophy. Cell, 80(1):167-78, 1995.

27. Rodrigues NR, Owen N, Talbot K, Ignatius J, Dubowitz V, Davies KE. Deletions in the survival motor neuron gene on $5 q 13$ in autosomal recessive spinal muscular atrophy. Hum Mol Genet, 4:631-4, 1995.

28. Zanoteli E, Beteta JT, Fireman MAT, Oliveira ASB, Gabbai AA, Perez ABA. Clinical aspects of type II and III spinal muscular atrophy (SMA) patients with deletion on SMNt gene. Neuromusc Dis, 11(6-7):647, 2001.

29. Campbell L, Potter A, Ignatius J, Dubowitz V, Davies K. Genomic variation and gene conversion in spinal muscular atrophy: implications for disease process and clinical phenotype. Am J Hum Genet, 61(1):40-50, 1997.

30. DiDonato CJ, Chen XN, Noya D, Korenberg JR, Nadeau JH, Simard LR. Cloning, characterization, and copy number of the murine survival motor neuron gene: homolog of the spinal muscular atrophy-determining gene. Genome Res, 7(4):339-52, 1997.

31. Andreassi C, Jarecki J, Zhou J, Coovert DD, Monani UR, Chen X, Whitney M, Pollok B, Zhang M, Androphy E, Burghes $\mathrm{AH}$. Aclarubicin treatment restores SMN levels to cells derived from type I spinal muscular atrophy patients. Hum Mol Genet, 10(24):2841-9, 2001.

32. Chang JG, Hsieh-Li HM, Jong YJ, Wang NM, Tsai CH, Li H. Treatment of spinal muscular atrophy by sodium butyrate. Proc Natl Acad Sci USA, 98(17):9808-13, 2001.

33. Humbert S, van Vuuren H, Lutz Y, Hoeijmakers JH, Egly JM, Moncollin V.p44 and p34 subunits of the BTF2/TFIIH transcription factor have homologies with SSL1, a yeast protein involved in DNA repair. EMBO J, 13(10):2393-8, 1994.

34. Burglen L, Seroz T, Miniou P, Lefebvre S, Burlet P, Munnich A, Pequignot EV, Egly JM, Melki J.The gene encoding p44, a subunit of the transcription factor TFIIH, is involved in large-scale deletions associated with Werdnig-Hoffmann disease. Am J Hum Genet, 60(1):72-9, 1997.

35. Moulard B, Salachas F, Chassande B, Briolotti V, Meininger V, Malafosse A, Camu W. Association between centromeric deletions of the SMN gene and sporadic adult-onset lower disease. Ann Neurol, 43:640-644, 1998.

36. Jackson M, Morrison KE, Al-Chabali A, et al. Analysis of chromossome $5 q 13$ genes in amyotrophic lateral sclerosis: homozygous NAIP deletion in a sporadic case. Ann Neurol, 39:796-800, 1996.

37. Weiner J. Curing the incurable. The New Yorker, 64-73, 2000.

38. Rowland LP. Six important themes in amyotrophic lateral sclerosis research. J Neurol Sci, 180:2-6, 1999. 